\title{
Role of Information Systems in Organizational Business Process
}

\author{
Margaret K. Kitone ${ }^{1}$ Omieno K.Kelvin ${ }^{2}$ \\ ${ }^{1}$ Jomo Kenyatta University of Agriculture and Technology, P.O. Box190-50100, Kakamega-Kenya \\ maggykads@gmail.com \\ ${ }^{2}$ Masinde Muliro University of Science and Technology, P.O. Box 190-50100, Kakamega -Kenya \\ komieno@acm.org
}

\begin{abstract}
Over the years, Information System has advanced so much that we are able to operate better in an organization which is better than what used to happen in the past. Information Systems derived from the term data processing. The purpose of Information Systems is to provide efficient and reliable ways on how to perform functions in an organization. Computers have important role in evolution of Information System. There have been a lot of applications of Information System in the organizations today including human resource operation as the main field of concern, accounting and finance, logistics and planning among others. Internet is the recent development in the use of Information. Studies have been carried out on Information System and its application but none of the studies have looked at the role Information System plays in typical organizational operational functions especially in the Human Resource Operations. This therefore leaves the gap in research that this paper sought to breach. The study is conducted through analysis of literature review from journals, and surveys. The paper therefore recommends that organizations should apply Information Systems in Human Resources operations in order to reap these benefits.
\end{abstract}

\section{Indexing terms/Keywords}

Information system (IS), Human Resource (HR), Human Resource Information System(HRIS)

\section{Academic Discipline And Sub-Disciplines}

Information Systems; Human Resources ;

\section{SUBJECT CLASSIFICATION}

Library of Congress Classification

TYPE (METHOD/APPROACH)

Literary Analysis;

\section{Council for Innovative Research}

Peer Review Research Publishing System

Journal: International Journal of Management \& Information Technology

Vol. 8, No. 1

editor@cirworld.com

www.cirworld.com, member.cirworld.com 


\section{INTRODUCTION}

A business process is a logically related set of activities that define how specific business tasks are performed. Business processes are the ways in which organizations coordinate and organize work activities, information, and knowledge to produce their valuable products or services. How well a business performs depends on how well its business processes are designed and coordinated. Well-designed business processes can be a source of competitive strength for an organization if it can use the processes to innovate or perform better than its rivals. Conversely, poorly designed or executed business processes can be a liability if they are based on outdated ways of working and impede responsiveness or efficiency. Information systems automate manual business processes and make an organization more efficient. Data and information are available to a wider range of decision-makers more quickly when information systems are used to change the flow of information. Tasks can be performed simultaneously rather than sequentially, speeding up the completion of business processes. Information systems can also drive new business models that perhaps wouldn't be possible without the technology.

Computers have become the foundation stone in the communities' cultures and in different fields of life. It is considered to be a tool for knowledge, and since nowadays is an information era, it's systems and searching for the best uses of it with the least effort and time, is the reason why the importance of information has increased in the current years due to the development in technology that was followed by the development of computers, which lead to saving time, effort and the rapid transformation of data and information to it's users.

Since it became acknowledged that organizations can be studied and analyzed according to the business processes they perform, process-based organizational analysis and design has become a prominent matter of study in both the management science and Information Systems (IS) fields. Apart from the focus on processes, the most distinctive characteristic of contemporary change management approaches is the heavy importance they generally place on the role of Information Systems in enabling process change. [1] asserts that, 'by virtue of its power and popularity, no single business resource is better positioned than information system to bring about radical improvement in business processes'. Computers are used in several ways, such as storing and data processing which is considered to be a vital element of the decision making elements especially in this field that is going to be studied in the in organization process which is the most important of information that the Information Systems as a structural factor and instrument transforms architect of organizations, and is increasingly integrated into Human resource operations. The importance of knowledge and human capital make extra suppression on Human Resource (HR) operations and new competencies for Organizational professionals are expected [2]

Institutions and companies in their different fields, whether it industrial, service, or productive companies use Information systems to provide suitable information and delivering it when needed to its users from the management levels of the company of the contributors. Due to this perspective, this term paper came along to acknowledge the role of Information System on the properties of Human Resource operations from the organizations point of view, through knowing the identity and quality of the Human Resource Information System that the organization seeks to gain and its importance in making congruent decisions.

By not using the computer in storing and processing the Human Resource operations could lead to problems associated with human mistakes, not taking full advantage and timing in a proper way, subsequently working on the ability to contribute in solving problems that Management could face by knowing and determining the most important features for the Human Resource Information System that could effect the management decisions. Information plays an important role in the transfer of mankind from ancient times to the resent, where this age is described as information era because of the importance of information in conducting of people life especially economically. So attention has increased toward information systems and investment in it to reach an accurate output, able to meet the user's needs, through the development, activation and increase the efficiency of its components [3]. Organizations must treat information as any other resource or asset. It must be organized, managed and disseminated effectively for the information to exhibit quality. Within an organization, information flows in four basic directions as upward, downward, horizontal and outward/inward [4]. Taking into account that there is a huge amount of information flow in organizations, it will be paramount to understand the importance of information systems and the roles in the organizations.

In order to be competitive in the information age an organization must have new capabilities [5]. As organization information technology infrastructure and core enterprise information on Human Resource Information System (HRIS), information as the management of information resources, networking and communications-based information system for the smooth operation of the organization, provide for the efficient operation of business process with sufficient information in real time.

In this paper, the Role of Information System on HR operations processes are studied. The paper seeks to identify the uses, role, and the importance of using information systems for effectiveness in organizations HR operations. The Human Resource Information Systems to support their decisions are the most important properties of the information systems and declaring the range of the achievements in these processes the user seeks to gain in order to make the right decisions. Therefore, the paper is aimed at discussing the role of Information System in effective HR operations. 


\section{THE OBJECTIVES}

This paper aims at the following objectives:
i. To establish the uses Information System in Human Resource Operations
ii. To establish the Role of Information System in Human Resource Operations
iii. To Establish the benefits derived from the use of the information System in Human Resource

\section{METHODOLOGY}

The paper is based on review of various discussions that have been conducted in various parts of the world. Discussions from various journals, books, magazines, websites have been taken. Data from various journals have been part of discussion. The advantage of the literature review drawn from other journals or past publication and books will help the researcher to explore deeply and identity the gaps which forms the bases of more research [6].

\section{DISCUSSION}

\section{Overview of Human Resource (HR)}

Human resource professionals initially relied on technology just for administrative tasks such as time, attendance and payroll. Information system today enhances many of the recruitment function's sub processes such as long and shortterm candidate attraction, the generation, pre-screening, and processing of applications or the contracting and on boarding of new hires[31 ]. Nowadays, HRIS provides human resource professionals with the time needed to direct their attention towards more business critical and strategic level tasks, such as leadership development and talent management [30]. HRIS, by producing, organizing, storing and distributing manpower information help the organization managers at various levels make proper decisions. In modern world, the majority of successful companies are using human resource information systems to support daily operations of human resources. HR professionals also rely on automated systems to direct employee benefit contributions. Such systems automatically direct a portion of workers' pay towards their retirement savings plans unless employees opt out, for instance. And while total rewards statements that alert employees to the total value of their compensation benefits packages being around for years, many organizations are now making that information available to workers electronically through HR information systems or self-service sites [28]

\section{Human Resource Information Systems (HRIS)}

Human Resource Information Systems (HRIS) is a process that utilizes the information technology for the effective management of human resource functions and applications. It is a computerized system typically comprising a data base or inter related data base that track employees and their employment specific information [29].It is an integrated system designed to provide information used in HR decision making [27]. Although an HRIS does not have to be computerized, but most are. [ 7] defined HRIS as a system used to acquire, store, manipulate, analyze, retrieve, and distribute information regarding an organization's human resources. An HRIS is not simply computer hardware and associated HR-related software. Although an HRIS includes hardware and software, it also includes people, forms, policies and procedures, and data. HRIS refers to a computerized system designed to manage the company's HR decisions. While information system has impacts on human resource (HR), at the same time managers, employees, customers and suppliers increase their expectancies for HR operations [7]. Effective management of a firm's human resources is a key source of competitive advantage for organizations. Increasingly, the delivery, support and management of HR all depend on technology specifically, human resource information systems. Research shows that implementing HRIS can enhance a company's long-term productivity and profitability. HRIS is not only increasing efficiency, they are also transforming the HR function. The importance of knowledge and human capital make extra suppression on HR and other functions in the organization. Computers have simplified the task of analyzing vast amounts of data, and they can be invaluable aids in HR management, from payroll processing to record retention. With computer hardware, software, and databases, organizations can keep records and information better, as well as retrieve them with greater ease [8]

\section{Purpose of HRIS}

An HRIS serves two major purposes in organizations. One relates to administrative and operational efficiency, the other to effectiveness. The first purpose of an HRIS is to improve the efficiency with which data on employees and HR activities is compiled. Many HR activities can be performed more efficiently and with less paperwork if automated. When on-line data input is used, fewer forms must be stored, and less manual record keeping is necessary. Much of the reengineering of HR activities has focused on identifying the flow of HR data and how the data can be retrieved more efficiently for authorized users. Workflow, automation of some HR activities, and automation of HR record keeping are key to improving HR operations by making workflow more efficient [8] 
The second purpose of an HRIS is more strategic and related to HR planning. Having accessible data enables HR planning and managerial decision making to be based to a greater degree on information rather than relying on managerial perception and intuition. For example, instead of manually doing a turnover analysis by department, length of service, and educational background, a specialist can quickly compile such a report by using an HRIS and various sorting and analysis functions. HR management has grown in strategic value in many organizations; accordingly, there has been an increased emphasis on obtaining and using HRIS data for strategic planning and human resource forecasting, which focus on broader HR effectiveness over time.

\section{Role of HRIS}

Cost decrease: Effects of IS on HR costs appear in several ways. First, it reduces costs of processes and works. For example, transforming from traditional HR to e-HR reduces costs of some HR applications, such as, postal cost, announcement cost and data processing cost [12]; [11]. Using self service technology reduces the processing costs of $\mathrm{HR}$ up to $75 \%$. E-selections and e-recruiting decrease costs of staffing and selections due to reduced employee turnover, reduced staffing costs, and increased hiring efficiency [13]. Second, using self service HR allows employees to perform their own work themselves directly. Thus, HR professionals spend less time on routine tasks [14].

Saving Time: IS allows HR professionals to spent less time on routine tasks [15] and make easier to acquire and analyze information [16]. For example, researches show that recruiting process shortens twelve days [14].

Increase in Efficiency: Intense use of IS aromatizes and standardizes routines. HR professionals may focus less on administrative activities and more on interpreting information. HR professionals may spend more time on other aspects of their jobs. Thus, HR professional can access more information, respond the problems in a timely major from managers and employees and evaluate the complex information more effectively [15]. Comparing with manual processes, reducing data errors, simplifying and fastening processes of HR practices make HRIS more advantageous [10];[11].

Enabling Communication and Collaboration: IS is a tool for effective communication and collaboration. E-mail, messaging, discussion lists, videoconferencing, virtual teams, electronic workgroups, and tele-working have changed the nature of workplace communication and collaboration. These make workplace interactions possible for employees even they are not physically present in the workplace. [17]. IS improves the skills of workers for collaborating, accessing information and decision making [18] Participative decision making becomes an organization-wide activity. Internet and web based technologies facilitate sharing of decision making responsibility through the organization hierarchy and structure [15]. HRIS as an integrated system also increases the capacity of reporting in the organization [19].

Competency Management: IS tools enable HR professionals both to reach larger candidate pool and make decision making more objective and effective to employ more relevant and competent candidates by means of decision making techniques in the selection and recruiting process. Improving and shortening the recruiting process increases competencies of incumbents and as a result quality of works. At the same time, because of distance access HR can be used to develop human capital of the organization effectively [12].

Knowledge Management: Knowledge management is a systematic process of acquiring, creating, capturing, synthesizing, learning, and using information, insights, and experiences to enhance decision making [20]. Knowledge management system is a natural extension of HRIS and HR development activities. HR professionals should integrate traditional HR functions into knowledge management [11]. Because organizations should acquire and manage organizational knowledge to prevent knowledge looses when employing. Using IS tools such as intranet, virtual collaborations, data storage and data mining can improve skills for knowledge acquisition and distributions [20]. These tools also facilitate knowledge participation and empower the specific task areas [18]. IS assists HR professionals to access and disseminate information more efficiently [15].

Structuring Strategic HR: Strategic role of HR focuses on aligning HR activities with HR strategies [21]. So, HR should work with managers and line managers in collaborations. IS is accepted as an important impetus for strategic HR. It builds stronger HR units and allows HR to engage in more significant strategic roles. IS solutions free HR from the burden of routine administrative tasks [22]. If HR professionals rely on IS, they hold a more strategic role. Because they will have time to interpret information, develop strategies and think about corporal transformation [15].

Adaptation of IS in HR functions has created new HR processes. These applications are e-learning, virtual recruitment, self service HR and portal technologies and new types of working. e-learning or web based training is a growing HR application [13]; [11]. IS tools can be used for formal and informal education activities like; e-mail, mail lists, dash boards, message systems, web pages, online courses, and media applications are some of business tools which support learning in workplace [17].

Virtual recruitment: Web based recruitment; virtual interview, CV searching, online psychological test and online job announcements have changed and fastened the recruitment process. These applications also removed the potential obstacles to reach larger candidate pool [11];15]. 
Self Service HR and portal applications: Employees can perform some of their own HR activities by means of accessing HRIS. This is called self service HR. Self service applications can include 60 percent of all HR activities [10]. Employees who use self-services can easily update and verify personal information, have information about internal job vacancies, access corporate handbooks, and receive notices about training programs. Managers can analyze candidate profiles, construct salary models, view benefits programs and monitor absentee trends. Moreover, performance appraisal and career development can be managed [23]. This also increases perceived quality of supplied HR services [9]. HR portals are complex information technology tools [24]. HR portals give the chance for each individual user to arrange or customize his or her own portal according to his or her own job responsibility or preferences [11].

Assist with decision making: The long-term success of an organization depends on the adequacy of its strategic plans. An organization's management team uses information systems to formulate strategic plans and make decisions for the organization's longevity and prosperity. The business uses information systems to evaluate information from all sources, including information from external references such as Reuters or Bloomberg for instance, which provide information on the general economy. This analysis of and comparison to market trends helps organizations analyze the adequacy and quality of their strategic decisions.

\section{Benefits of HRIS integration in Organizational Business processes}

There are several benefits to organizations in using HRIS [25]. They include the following: Providing a comprehensive information picture as a single, comprehensive database; this enables organizations to provide structural connectivity across units and activities and increase the speed of information transactions [26]. Increasing competitiveness by improving HR operations and improving management processes. Collecting appropriate data and converting them to information and knowledge for improved timeliness and quality of decision making. Producing a greater number and variety of accurate and real-time HR-related reports. Streamlining and enhancing the efficiency and effectiveness of HR administrative functions. HRIS increase efficiency and reduce costs. Efficiency comes from automating existing processes, using software that generates a better and more intuitive user experience, more self-service, and reduced HR staffing which requires expertise in process design, organization design, and work design. It offers tremendous potential for improving performance in most firms. There is increased Effectiveness. Effectiveness is increased by outsourcing work that is done more efficiently and effectively by outside vendors specializing in a given process or set of activities. Almost all HR functions outsource some activities today, with payroll, benefits administration, and sourcing of recruits most commonly outsourced. It transforms the HR role. It Shifts the focus of HR from the processing of transactions to strategic HRM. HR leaders often hope that the function will gain a greater strategic perspective on the business and play a more impactful role than before the adoption of the new technology. The primary way in which HRIS spur HR transformation is through robust reporting and analytic capabilities. There is broad recognition that new different HR capabilities are needed to elevate the role of HR. HR metrics need to help executives manage the business for example, ways to change the cost structure of the firm or identification of key types of talent that are critical for business success, not simply reflect the efficiency of HR processes for example, time to fill job openings or percentage of employees receiving training in a given year. Reengineering HR processes and functions Improving employee satisfaction by delivering HR services more quickly and accurately to them. From the use of dashboards to display key metrics graphically and in real time, to tools for analyzing and reporting on results from complex, disparate datasets, HRIS ups the HR game.

\section{CONCLUSION AND RECOMMENDATION}

Human resource information systems have dramatically altered how HR services are delivered and managed by organizations. By automating Human Resource practices, HRIS will save time and money, effectively reallocate work processes and thus provide competitive advantage and add strategic value to the organization. Implementing IS within an organization can prove to be costly but the benefits and its role are far much reaching than not adopting the system. HR is tied to the broader process of strategic planning, beginning with identifying the philosophy and mission of the organization. Human resources can provide a core competency for the organization, which may represent unique capabilities of the organization. The HR unit has major responsibilities in HR planning, but managers must provide supportive information and input. An HRIS is an integrated system designed to improve the efficiency with which HR data is compiled and to make HR records more useful to management as a source of information. An HRIS offers a wide range of HR uses, with payroll, benefits administration, and Equal Employment Opportunity affirmative action tracking being the most prevalent. Information on past and present conditions is used to identify expected future conditions and forecast the supply and demand for human resources. Modern business organizations have been investing increasingly substantial amounts of money in information systems with the objective of improving their operational efficiency and competitive ability in the industry. IS investments can really promote the organizational operational performance by reducing costs, raising profit margin, upgrading production levels, increasing service quality, advancing customer satisfaction and improving overall operations hence contributing to the development and growth of the country's economy.

\section{REFERENCES}


[1] Davenport, T.H. 1993. Process Innovation: Reengineering Work through Information Technology, Harvard Business School Press, Boston

[2] Omar F.U., Mehmet, M. 2013. "The Impact of Information Technology on Human Resource Practices and Competencies". 1Suleyman Demirel University FEAS Social Work Department 2Dicle University FEAS Department of Management , Emails: omerunal@sdu.Edu.tr,mehmetmete@hotmail,com

[3] Enas, M.S.,Ayman, M., Majed, A.,Khalil, M.A. 2012. The Effect of Using Computer on the Properties of the Accounting Information from the Investors' Point of View (Studying Amman's Financial Market Situation). Interdisciplinary Journal of Contemporary Research in Business: Vol. 3/11.ljcrb.webs.com.

[4] Haag, S., \& Cummins, M. 2008. Management Information System for the Information Age. NewYork, USA: MacGraw Hill.

[5] Yang, F. 2012 School of Finance, Shandog Polytechnic University, Jinan, China, Research on the Impact of Accounting Information on Accounting Theory and Practice.

[6] Mugenda, O., Mugenda A.G., 2003. Research Methods: Quantitative and Qualitative Approaches, Acts Press, Nairobi

[7] Kavanagh, M.J.,Mohan, T. 1990. Introduction of Human Resource Management: Human Resource Information System and the Role of Information Technology Boston: PWS-Kent.

[8] Nicholas A.B., Christopher M.L., Kim, L. 2005. The Impact of Human Resource Information Systems: An Exploratory Study in the Public Sector Vol. 5/4: Communication of the IIMA.

[9] Mohammed, A.,Abu,R. 2013. The Impact of Management Information Systems of Human Resources on the Training Needs in Al-Balqa Applied University; Department of Business Administration: Al Balqa Applied University, Salt-Jordan. Email: abusharare 77@hotmail.com.

[10] Ulrich, D., Younger, J. \& Brockbank, W. 2008. The Twenty-First Century HR Organization, Human Resource Management Journal, 34,473-495

[11] Hendrickson, 2003. Human resource information systems: Backbone technology of contemporary human resources, Journal of Labour Research, 24(3), pp.381-394.

[12] Lin, L.H. 2011. Electronic Human Resource Management and Organizational Innovation: the Roles of Information Technology and Virtual Organizational Structure; The International Journal of Human Resource Management, 22/2, 235-257

[13] Strohmeier, S. 2007. Research in e-HRM: Review and Implications, Human Resource Management Review, $17,19-37$

[14] Baloh and Trkman, 2003. Influence of Internet and Information Technology on Work and Human Resource Management, Informing Science, June, 498-505.

[15] Gardner, S.D., Lepak, D.P. and Bartol, K.M. 2003. Virtual HR: The Impact of Information Technology on the Human Resource Professional, Journal of Vocational Behaviour, 63/2, 159-179.

[16] Bell, B.S.Lee, S.W. and Young, S.K. 2006. The Impact of eHR on Professional Competence in HRM: Implications for the Development of HR Professionals, Working Paper Series, Cornell University School of Industrial and Labour Relations Center for Advances Human Resources Studies, http://digitalcommons.ilr.cornell.edu/cgi.

[17] Benson, A.D., Johnson, S.D., Kuchinke, K,P. 2002. The Use of Technology in the Digital Workplace: A Framework for Human Resource Development, Advances in Developing Human Resources 4/4,392-404.

[18] Tafti, A., Mithas, S and Krishnan, 2009. Complementaries Between Information Technology and Human Resource Practices in Knowledge work, WISE 2009.

[19] Dessler, 2008. Human Resource Management . Pearson-Prentice Hall, New Jersey.

[20] Ardichvili, A. 2002. Knowledge Management, Human Resource Development, and Internet Technology, Advances in Developing Human Resources, 4/4, 451-463.

[21] Conner and Ulrich, 1996. "Human Resource Roles: Creating Value Not Rhetoric" (Human Resource Planning, vol 19 No. 3, pp 38-39).

[22] Haines III and Lafleur, 2008. Information Technology Usage and Human Resource Roles and Effectiveness, Human Resource Management, 47/3, 525-540.

[23] Lippert and Swiercz, 2005. Human Resource Information Systems (HRIS) and Technology trust, Journal of Information Science, 31/5, 340-353. 
[24] Ruta, 2005. The application of Change Management Theory to HR Portal Implementation in Subsidiaries of Multinational Corporations, Human Resource Management, 44.1, 35-53.

[25] Beckers, A. M., \& Bsat, M. Z. (2002). A DSS Classification Model for Research in Human Resource Information Systems. Information Systems Management, 19/3, 41-50.

[26] Lengnick-Hall, C. A., \& Lengnick-Hall, M. L. (2006). HR, ERP, and Knowledge for Competitive Advantage. Human Resource Management, 45(2), 179-194.

[27] Luck, B. (2010) Innovation of Technology: Business for a New Century, www.scribd.com/doc/27947709/Innovation-of-Technology-in-Business-Slides, (01. 01. 2012).

[28] A publication Journal , 2013. InterDisciplinary Journal of Contemporary Research in Business, February, Vol. 4/10

[29] Gill, J., Johnson, P., (2010). Research methods of managers, Sage Publications Limited, Fourth Edition.

[30] Lengnick-Hall, Mark L., Moritz Steve (2003). The impact of e-HR on HRM function. Journal of Labor Research 24(3), 365-379.

[31] Keim, T., \& Weitzel, T. (2009). An adoption and diffusion perspective on HRIS usage. In T. Coronas \& M. Oliva (Ed.), Encyclopedia of Human Resources Information Systems: Challenges in E-HRM (pp. 18-23). Hershey, PA: IGI Global.

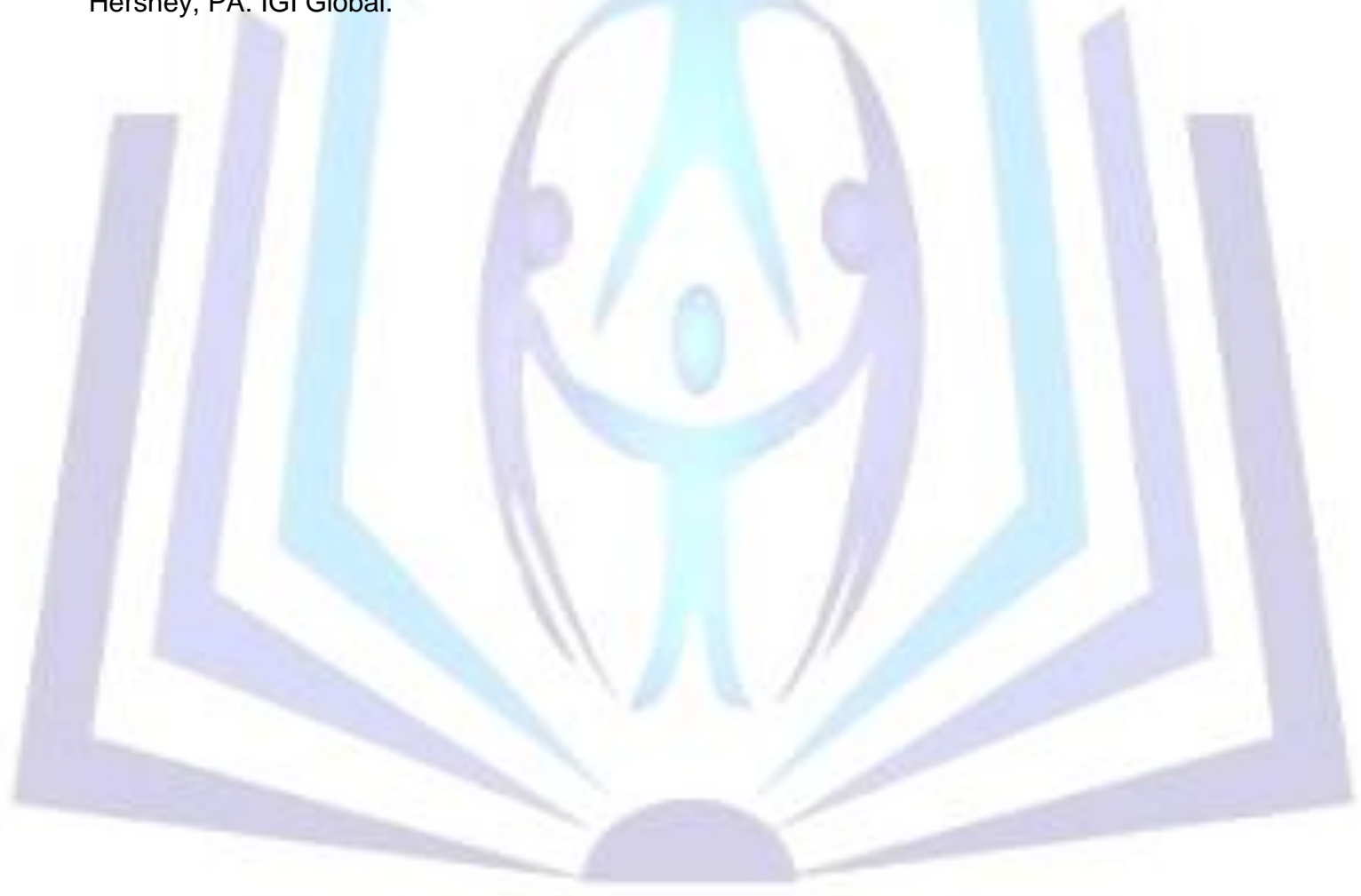

